\title{
Desenvolvimento moral e manifestações de polidez
}

Fernanda C añete Vebber*

R esumo: Estetexto propõe uma reflexão sobrea dimensão moral no âmbito educacional, buscando compreender uma possível relação entre desenvolvimento moral emanifestações de polidez. D iferentes perspectivas no campo da psicologia têm-se ocupado do estudo da moralidade, destacando-se a abordagem construtivista pelo viés de J ean Piaget e de sua obra 0 juízo moral na criança. $\mathrm{N} \mathrm{a}$ relação entre desenvolvimento moral e manifestações de polidez, entende-se que há algo de moral na polidez, visto que ela traduz atitudes respeitosas e de consi deração pelo outro, e que ela parece ter uma importante função no início do desenvolvimento moral como um conteúdo a ser aprendido.

Palavras-chave: D esenvolvimento moral, Polidez, Jean Piaget.

A bstract: This paper proposes a reflection on themoral dimension in education, seeking to understand a possible relationship between moral development and expressions of politeness. D ifferent perspectives in the field of psychology has been busy studying the morality, especially the constructivist approach by the bias of J ean Piaget and his work T hemoral judgment in children. The relationship between moral development and expressions of politeness, it is understood that there is something of morality in politeness, as it reflects attitudes respectful and consideration for others, and she seems to have an important role in early development as a moral content to be learned.

Keywords: M oral development, Politeness, J ean Piaget.

Psicóloga e Psicopedagoga do Serviço de Orientação Educacional do Colégio Santa Rosa de Lima, Porto Alegre, RS. M estranda em Educação - Programa de Pós-Graduação em Educação/U FR GS. E-mail: canete@ibest.com.br 
Certo dilema tem sido observado na relação entre as famílias e as escolas. Os educadores parecem esperar que os alunos cheguem à escola polidos ${ }^{1}$ e respeitem uns aos outros. $0 \mathrm{~s}$ pais, por outra perspectiva, parecem depositar na escola a responsabilidade de tornar seus filhos pessoas bem-educadas. É uma questão que se coloca em uma dimensão ética, na medida em que parece não haver mais algo que una famílias e escolas, parece não haver um consenso do que seja educação e das funções a serem desempenhadas por tais instituições.

L a Taille (2004, p. 106) dá ênfase a uma questão que Ihe parece central e merece maiores reflexões: "deve, ou não, a escola comprometer-se oficialmente, com objetivos explícitos e programas claros, com a formação ética dos alunos?". Os Parâmetros Curriculares $\mathrm{N}$ acionais propõem um tema transversal específico sobre ética, o qual é pouco citado nas pesquisas e artigos acadêmicos, e nesses se observa que são praticamente inexistentes propostas educacionais de formação ética e educação moral, conforme 0 estudo realizado por La Taille (2004).

$\mathrm{N}$ ão sendo o objetivo aqui aprofundar essa questão, nem mesmo responder ao dilema, mostra-se importante situá-lo, para que possamos pensar na dimensão moral dentro das escolas e no exercício da docência. Q ue relatos já estão banalizados a respeito da realidade das escolas públicas brasileiras? Os relatos de situações de violência física e, especialmente, psicológica entre professor e aluno têm sido bastante comuns.

0 professor está na sala de aula para educar, para ensinar os seus alunos. 0 professor ensina muito além daquilo que os conteúdos escolares lhe incubem. 0 modo como recebe diariamente seus alunos, dizendo ou não, "bom dia", o tom de voz que utiliza para se comunicar com os alunos, a forma como resolve os conflitos, o jeito como faz as solicitações aos seus educandos, 0 olhar que lança sobre a turma, enfim, tudo isso está nas entrelinhas. A ética e a moral são ensinadas nas entrelinhas. $N$ ão são

1 A polidez é tratada costumeiramente, em nossa sociedade, como educação. A gir com polidez significa agir com boa educação. 
disciplinas que façam parte da matriz curricular de ensino, mas certamente são conteúdos a serem desenvolvidos em sala de aula. A grande questão é saber como tem sido tratada a dimensão ética nas escolas, e como os professores compreendem o desenvolvimento moral e sua possível relação com manifestações de polidez.

No campo da psicologia, diferentes perspectivas teóricas têm estudado a moralidade, na tentativa de responder como a criança se torna capaz de agir moralmente. Tais perspectivas apre sentam concepções distintas sobre a moralidade humana, utilizando diferentes critérios sobre o desenvolvimento moral, o qual é associado a fatores e mecanismos diferenciados (BIAGGIO, 1985; LOUREN ÇO, 1992).

A abordagem psicanalítica enfatiza o teor emocional da moralidade, e a comportamental realça justamente o componente comportamental da moralidade, e ambas desvalorizam a consciência. A abordagem construtivista tende a salientar 0 componente cognitivo da moralidade e a tratar a moral vinculada à consciência (FREITAS, 2003; KOH LBERG; PIAGET apud LOUREN ÇO, 1992). O enfoque construtivista entende o desenvolvimento moral como uma construção do sujeito em interação com o meio e não um mero produto das influências diretas do ambiente.

A Epistemologia Genética de J ean Piaget (1896-1980), teoria construtivista, compreende o estudo da gênese do conhecimento, sendo o estudo da moralidade inseparável de sua teoria do conhecimento (FREITAS, 2003).

A obra de Piaget 0 juízo moral na criança surgiu em uma época em que a teoria psicanalítica e as teorias da aprendizagem social predominavam na investigação da moralidade, contribuindo para a construção de uma abordagem alternativa sobre a moralidade (FR EITAS, 2003). As ideias de L awrence Kohlberg sobre o julgamento moral difundiram-se para além da psicologia e deram visibilidade ao tema da moralidade.

D e acordo com L ourenço (1992), a abordagem construtivista é a mais apropriada para o estudo do desenvolvimento 
psicológico do ponto de vista individual e a que mais permite visionar a transformação da sociedade. É a perspectiva que vislumbra um sujeito com potencial para se desenvolver qualitativamente nas dimensões afetivas e intelectuais.

\section{O juízo moral na criança}

De acordo com Freitas (2002), o juízo moral na criança pode ser compreendido como um estudo psicogenético sobre as relações entre o respeito e a lei moral e uma primeira tentativa de Piaget de submeter as suas ideias sobre a moral a uma verificação empírica.

Diversos estudiosos da moralidade (KAN T; DU R K H EIM ; BOVET apud PIAGET, 1994) concordam que o respeito é 0 sentimento fundamental da vida moral. Pode ser considerado 0 sentimento formador da consciência moral.

Entendendo que "toda moral consiste num sistema de regras" e que "a essência de toda moralidade deve ser procurada no respeito que o indivíduo adquire por essas regras", Piaget (1994, p. 23) inicia seu estudo sobre a moralidade por meio do jogo de regras. Interessa-lhe saber o tipo de relação que a criança estabelece com o seu meio social, visto que o respeito é um sentimento que se desenvolve em decorrência dessa interação. Piaget (1994) compara as relações existentes entre a prática e a consciência da regra, considerando que tais relações são as que melhor permitem definir a natureza psicológica das realidades morais, e chega a uma hi pótese que orientará a continuidade desse estudo. H á dois grupos de realidades sociais e morais: de um lado, a coação e o respeito unilateral e, de outro, a cooperação e o respeito mútuo.

Piaget (1994), em concordância com o psicólogo Pierre Bovet, diz-nos que o respeito provém das relações dos indivíduos entre si. O respeito unilateral, a primeira forma de respeito presente no desenvolvimento humano, constitui-se nas relações de coação social. 
Por temer perder o amor das pessoas que ama, a criança se sente obrigada a respeitá-las. Segundo Ferenczi (apud FR EITAS, 2002), as crianças obedecem a seus pais porque existe uma relação de amor entre eles que faz com que a criança obedeça de bom grado. Bovet ePiaget defendem que éporque respeita as pessoas que a criança adquire respeito pelas leis.

A partir do respeito unilateral, outras formas superiores de respeito são possíveis, sendo o respeito unilateral condição fundamental para o desenvolvimento moral, mas não suficiente. "O respeito mútuo é a forma de equilíbrio para a qual tende o respeito unilateral", assim como "a cooperação constitui a forma de equilíbrio para a qual tende a coação" (PIAGET, 1994, p. 83).

Conforme Freitas (2002), os resultados das pesquisas sobre as regras do jogo levam Piaget a sustentar a tese kantiana da existência de duas morais: a moral da heteronomia e a moral da autonomia, além de sugerir a existência de um processo evolutivo em direção à segunda.

\section{A polidez: uma pequena virtude}

A polidez é definida por L a Taille (2001, p. 96) como "formas de falar e/ou de agir convencionais, nas relações sociais, como falar bom dia, desculpe, obrigado", sendo que tais formas não são universais, visto que divergem, por vezes, em seu conteúdo, de acordo com o grupo, comunidade ou sociedade a que estejam convencionadas. Turiel (apud L O U REN ÇO, 1992) tratou dessas formas de interação social como convenções sociais, isto é, uniformidades comportamentais que pretendem regular a interação social.

La Bruyère (apud COM TE-SPON VILLE, 1993, p. 19) diz que a polidez faz o homem parecer por fora com aquilo que deveria ser interiormente; mostra que "dizer por favor é aparentar respeitar; dizer obrigado é aparentar estar agradecido". Por essa razão, ressalta Comte-Sponville (1993), a polidez énecessária na criança e insuficiente no adulto. Parece muito pior um 
adulto cruel do que uma criança mal-educada. Sendo assim, a manifestação de comportamentos polidos em adultos parece nos dizer muito pouco sobre seu desenvolvimento moral, visto que, como uma convenção social, não pressupõe sinceridade (LA TAIL LE, 2001).

L a Taille (2001) concorda com Comte-Sponville ao afirmar que a polidez é a mais pobre, mais superficial e discutível das virtudes, mas tem seu valor, e como tal merece pelo menos o título de "pequena virtude".

\section{Desenvolvimento moral e manifestações de polidez}

Comte-Sponville (1993, p. 17) diz que "a moral no princípio é apenas polidez, submissão aos costumes, à regra instituída (...). 0 costume é anterior ao valor, à obediência, ao respeito, e a imitação, ao dever".

Q ue relação é essa entre a moralidade e a polidez? Será que a polidez prepara a moralidade ou simplesmente a antecede?

Ao abordar o desenvolvimento moral ea polidez nas crianças, La Taille (2001) indaga-se sobre a existência de alguma relação entre a moralidade e a polidez e procura encontrar respostas em um estudo realizado com 90 crianças, de distintas faixas etárias. La Taille (2001) revela em seus resultados que, pelo menos no início do desenvolvimento moral, a avaliação do caráter das pessoas, baseada na expressão de comportamentos polidos ou na sua falta, é indissociável da avaliação moral, pautadas em atos de generosidade, honestidade ou coragem, visto que, para as crianças pequenas, a falta de polidez é um indício confiável para serem previstas outras transgressões. Já para as crianças de doze anos, tal certeza desaparece por completo.

La Taille (2001) entende que há algo de moral na polidez, pois, mesmo que superficiais e não sinceras, as diversas formas de polidez podem traduzir atitudes respeitosas e de consideração pelo outro. Conclui também, dentre outros dados, que a polidez 
pertence ao universo moral das crianças de seis a doze anos. Os resultados de sua pesquisa o levam a pensar que a polidez tem um papel relevante na gênese da moralidade, pois "pertence ao conjunto de valores e regras com os quais a criança penetra o universo moral e sobre os quais reconstrói esse universo em direção à autonomia" (LA TAILLE, 2001, p. 113).

"A polidez ('isso não se faz') é, portanto, anterior à moral ('não se deve fazer isso'), que se constituirá somente pouco a pouco, como uma polidez interiorizada, liberada de aparências e de interesses, einteiramente concentrada na intenção" (CO M TESPO N V ILLE, 1993, p. 18). Comte-Sponville (1993) diz que a polidez é o caminho inicial para que uma criança se torne virtuosa. "As boas maneiras antecedem as boas ações" (CO M TE SPO N V ILLE, 1993, p. 18).

A moral começa, conforme Comte-Sponville (1993), pelo mais baixo, a polidez. A virtude é algo que se aprende, é preciso se tornar virtuoso. A ristóteles explica que por meio do hábito se aprende a ser virtuoso. Tal argumento mostra-se insuficiente, e Kant busca esclarecêlo com maiores detalhes, explicando esse início da virtude por uma exigência externa: aquilo que a criança não pode fazer por si mesma é preciso que os outros façam por ela (CO M TE-SPO N V IL LE, 1993). Puig (1998), mesmo entendendo que a moralidade não se reduz à obediência cega a regras, insiste que a aquisição da virtude não é tanto um produto da autonomia moral, mas de certa forma de submissão. "A virtude supõe (...) a aceitação de critérios que não foram criados pela própria pessoa e a obrigatoriedade ao exercício e à prática desses crité rios externos" (PUIG, 1998, p. 64). Essa visão teleológica, que remonta ao tempo de Aristóteles, possibilita visualizar melhor a polidez como uma virtude.

Então, poder-se-ia questionar que, se a criança, desde pequena, aprende formas de polidez, ela se tornará um adulto moralmente autônomo. Q uanto ao papel que a aprendizagem das formas de polidez desempenha no desenvolvimento moral das crianças, há estudos que mostram que as crianças pequenas, de três ou quatro anos, já distinguem normas morais, como roubar, 
e convenções sociais, como falar bom dia (TURIEL apud L OU REN ÇO, 1992). Freud, Kohlberg e Piaget, principais autores da psicologia moral, parecem concordar com a tese de que a moral propriamente dita faça parte do universo infantil somente a partir dos oito ou nove anos, e que a imposição de certas formas de conduta, como a polidez, antecedem-na, mas não a preparam (LA TAILLE, 2001).

L evando em consideração a perspectiva construtivista, a polidez desempenha alguma função no desenvolvimento moral, pois as estruturas superiores se alimentam das formas e dos conteúdos das inferiores (PIAGET, 1990). Sendo assim, a criança inicia a aprendizagem de boas maneiras a partir da imitação de modelos, os quais não são suficientes, apesar de necessários. A aprendizagem da polidez, portanto, parece ser uma condição importante para o desenvolvimento moral, mas não determinante, já que é possível se desenvolver moralmente sem ter aprendido como se comportar polidamente. Assim como a heteronomia cumpre um papel no desenvolvimento do sujeito autônomo, a polidez parece ter uma função no início do desenvolvimento moral como um conteúdo a ser aprendido, o qual introduzirá o sujeito no universo da moral.

Tudo o que até então foi apresentado parece mostrar que, apesar de ser uma pequena virtude e de estar presente no desenvolvimento moral infantil, a polidez não seria um prérequisito para o desenvolvimento da moralidade, mas estaria implicada em seus primórdios como um conteúdo a ser aprendido. Sendo assim, a escola mostra-se como um espaço privilegiado para que crianças e jovens sigam se desenvolvendo também moralmente.

\section{Referências}

BRASIL. M inistério da Educação e Cultura. Parâmetros Curriculares N acionais. Brasília: Secretaria de E ducação Fundamental, 1997. 
COMTE-SPO N V ILLE, André. A pequena virtude. In: DH OQU OIS, Regine (org. ). A polidez: virtude das aparências. Porto A legre: $L \& P M$, 1993.

FREITAS, Lia. Piaget e a consciência moral: um kantismo evolutivo? Psicologia: R eflexão eC rítica. Porto A legre, v. 15, n. 2, p. 303-308, 2002.

FREITAS, Lia. A moral na obra de Jean Piaget: um projeto inacabado. São Paulo: Cortez, 2003.

LA TAILLE, Y ves de. Desenvolvimento moral: a polidez segundo as crianças. C adernos de Pesquisa, n. 114, p. 89-119, nov. 2001.

LA TAIL LE, Yves de; SO UZA, L ucimara; VIZIO LI, L etícia. Ética e Educação: uma revisão da literatura educacional de 1990 a 2003. Educação e Pesquisa. São Paulo, v. 30, n. 1, p. 91-108, jan./abr. 2004.

LOUREN ÇO, O rlando. Psicologia do desenvolvimento moral: teoria, dadose implicações. Coimbra: Almedina, 1992.

PIAGET, Jean. 0 juízomoral na criança. 3.ed. São Paulo: Summus, 1994.

PIAGET, Jean. E pistemologia G enética. São Paulo: M artinsFontes, 1990.

PU IG, J osep. A construção da per sonalidademoral. São Paulo: Ática, 1998. 
